\title{
GEOLOGIA DA FOLHA TOPOGRÁFICA GUAPIARA NA ESCALA 1:50.000.
}

\author{
GEOLOGY OF GUAPIARA TOPOGRAPHIC SHEET IN 1:50.000.
}

\author{
Otávio Augusto Ruiz Paccola VIEIRA ${ }^{1}$, Antonio Misson GODOY ${ }^{2}$, Peter Cristian \\ HACKSPACHER ${ }^{2}$, Washington Barbosa LEITE JUNIOR ${ }^{2}$ \\ ${ }^{1}$ Programa de Pós-graduação em Geologia Regional, Instituto de Geociências e Ciências Exatas, Universidade Estadual Paulista, \\ UNESP, Rio Claro, São Paulo, Brasil. Email: otaviovieirageo@gmail.com \\ ${ }^{2}$ Departamento de Petrologia e Metalogenia, Instituto de Geociências e Ciências Exatas, Universidade Estadual Paulista, UNESP, \\ Rio Claro, São Paulo, Brasil. Emails: mgodoy@rc.unesp.br; phack@rc.unesp.br; wleite@rc.unesp.br
}

\author{
Introdução \\ Geologia Regional \\ Geologia Local \\ Geologia Estrutural \\ Metamorfismo \\ Conclusões \\ Agradecimentos \\ Referências
}

\begin{abstract}
RESUMO - A região da Folha Topográfica de Guapiara situa-se no extremo sul do estado de São Paulo e está compreendida na porção central da Província Mantiqueira na faixa centro-sul do Cinturão Ribeira. O arcabouço geológico local envolve rochas da sequência metavulcanossedimentar do Supergrupo Açunguí, de idade meso- a neoproterozoicas deformadas e metamorfizadas no Neoproterozoico, associadas a rochas granitoides geradas durante os episódios colisionais ligados ao Ciclo Brasiliano e à formação do Supercontinente Gondwana. As principais unidades litoestratigráficas são constituídas pelos metassedimentos da Formação Água Clara e dos grupos Votuverava e Itaiacoca de idade meso- a neoproterozoica, corpos graníticos neoproterozoicos representantes do Granito Três Córregos e do Granito Capão Bonito, rochas sedimentares do Grupo Itararé, intrusivas básicas associadas ao Magmatismo Serra Geral e sedimentos recentes quaternários. O quadro estrutural-metamórfico é determinado pelo arranjo tectônico final neoproterozoico, evidenciado nas rochas epimetamórficas por uma evolução estrutural do tipo polifásica, com quatro fases de deformação $\left(S_{n}, S_{n+1}, S_{n+2}\right.$ e $\left.S_{n+3}\right)$ e três eventos metamórficos $\left(M_{1}, M_{2}\right.$ e $\left.M_{3}\right)$, de caráter regional progressivo, contato e regional a localmente dinâmico de natureza retrometamórfica.

Palavras-chave: geologia, análise estrutural, mapeamento geológico, Guapiara.
\end{abstract}

\begin{abstract}
Geology of Guapiara Topographic Sheet in 1:50.000. The region of Guapiara Topographic Sheet is located in the extreme South of the São Paulo state and it is comprised in the central portion of the Mantiqueira Province in the South-central zone of the Ribeira Belt. The local geological framework involves rocks from the metavulcanic sedimentary sequence of the Açunguí Supergroup, Meso- to Neoproterozoic age, deformed and metamorphosed in the Neoproterozoic, associated with granitoid rocks generated during the collisional episodes related to the Brasilian Cycle and to the Gondwana Supercontinent formation. The main lithostratigraphic units are composed of the Água Clara Formation and the Votuverava and Itaiacoca groups metassediments of Mesoproterozoic age, Neoproterozoic granite bodies representing the Três Córregos Granite and the Capão Bonito Granite, Itararé Group sedimentary rocks, associated intrusive rocks of the Serra Geral Magmatism and recent Quaternary sediments. The structuralmetamorphic framework is determined by the Neoproterozoic final tectonic arrangement, evidenced in the epimetamorphic rocks by a polyphase structural evolution, with four deformation phases $\left(S_{n}, S_{n+1}, S_{n+2}\right.$ e $\left.S_{n+3}\right)$ and three metamorphic events $\left(M_{1}, M_{2}\right.$ and $\left.M_{3}\right)$ of a regional progressive, contact and regional to locally dynamic of a retrometamorphic nature feature, respectively.
\end{abstract}

Keywords: geology, structural analysis, geological mapping, Guapiara.

\section{INTRODUÇÃO}

A região sul do Estado de São Paulo, o Vale do Ribeira, ainda é uma das áreas mais carentes em termos de conhecimento geológico regional. Isto se deve, em grande parte, às dificuldades de acesso e, em grande parte, pela cobertura por reservas florestais do Parque Estadual de Jacupiranga, no Planalto do Alto Turvo. A região de Guapiara representa uma área de extrema importância geológica no contexto tectônico regional, na qual se articula a junção entre os terrenos Apiaí, Curitiba e Luís Alves, separados por importantes zonas de cisalhamento.

Os primeiros trabalhos publicados desta região e proximidades estão voltados para atividades de prospecção pelo Departamento Nacional de
Pesquisa Mineral, a partir de mapeamento geológico da Folha Capão Bonito e de áreas municipais do entorno da Folha Guapiara. Posteriormente, foi realizado o mapeamento geológico da Folha Capão Bonito em escala 1: 50.000 por Chiodi Filho et al. (1983).

A geologia da região está definida nos mapas geológicos de integrações do estado de São Paulo em escala 1: 500.000 elaborado pelo Instituto de Pesquisa Tecnológica - IPT (Bistrichi et al., 1981; Almeida et al., 1981) e no mapa em escala 1: 750.000 elaborado pela Companhia de Pesquisa de Recursos Minerais (CPRM, 2006).

Os principais trabalhos regionais apresentam enfoque na tentativa de correlacionar as 
diversas sequências de rochas metassedimentares separadas por zonas de cisalhamento (Soares, 1987, 1988; Campanha et al., 1987; Campanha, 1991; Basei et al., 1992; Reis Neto, 1994; Siga Junior, 1995; Fassbinder, 1996; Campanha \& Sadowski, 1999).

Este trabalho tem o propósito de apresentar

os dados resultantes da investigação geológica e estrutural da área geográfica da Folha Topográfica de Guapiara (SG-22-X-B-II-2) em 1:50.000 (Figura 1), definindo cada unidade litotectônica (terreno tectono-metamórfico), separadamente, em termos de sua evolução petrológica, magmática-metamórfica e microestrutural (Vieira, 2017).

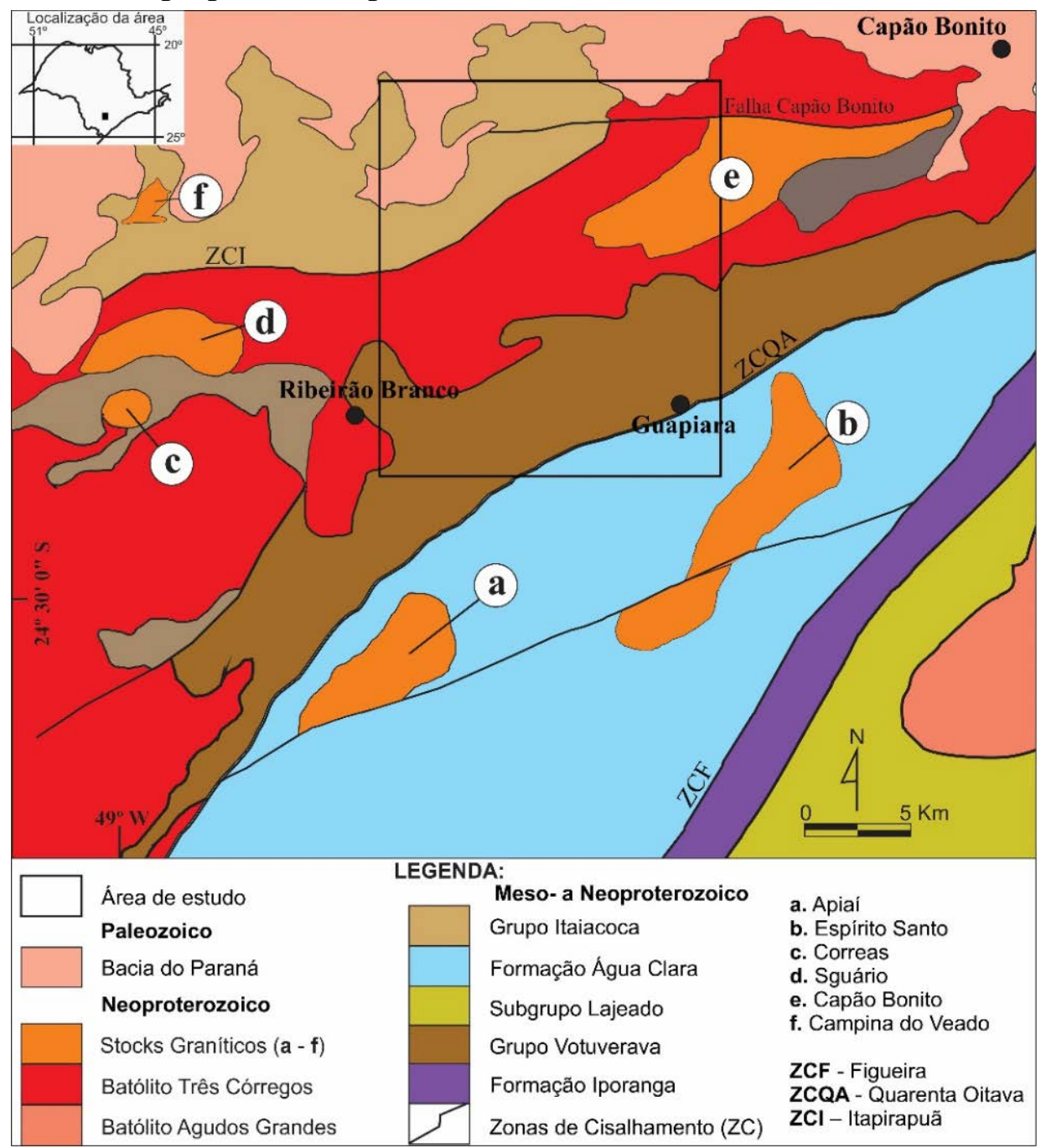

Figura 1 - Mapa geológico regional simplificado e localização da Folha Guapiara. Mod. de Prazeres Filho et al. (2003).

\section{GEOLOGIA REGIONAL}

Os processos sedimentares, tectônicos e metamórficos que configuram a evolução geológica da área mapeada mostram-se intimamente ligados aos eventos atuantes no Terreno Apiaí em contexto da fragmentação do Supercontinente Rodínia, da consequente instalação da Tafrogênese Toniana (Fuck et al., 2008; Brito Neves, 1999) e posterior formação do Gondwana, durante a Orogênese Brasiliana. Tal ciclo de ruptura e instauração de supercontinentes, segundo Hasui (2010, 2012), abrange os principais aspectos geotectônicos: deriva de massas continentais, abertura de oceanos, convergência de massas continentais, colisão de continentes, orogênese, metamorfismo e magmatismo e colapso do orógeno.

A área insere-se na Província Mantiqueira (Almeida, 1967; Hasui \& Oliveira, 1984), na região sul do Cinturão de Dobramentos Sudeste. A Província Mantiqueira Central (Heilbron et al., 2004) é subdividida em grandes compartimentos geotectônicos que são construídos e justapostos a partir da movimentação horizontal e vertical ao longo das zonas de cisalhamento de direção NESW.

A Província da Mantiqueira Central foi 
definida inicialmente por Almeida et al. (1977, 1981). Nos anos decorrentes, essa classificação passou a ser referida como correspondente a três cinturões orogênicos Araçuaí, Ribeira e Tijucas, respectivamente (Hasui et al., 1978; Hasui, 2010).

O Cinturão Ribeira inicialmente definido por Almeida et al. (1973) compreende um largo segmento crustal paralelo à linha costeira do sudeste brasileiro, que foi amalgamado, deformado e metamorfizado durante a Orogenia Brasiliano-Pan-Africana (Neoproterozoico ao Paleozoico).

A estruturação do Cinturão Ribeira é controlada por um sistema de cisalhamento transcorrente destral de escala continental (Campanha \& Sadowski, 1999; Campanha, 2002; Faleiros, 2008, Faleiros et al. 2010, 2011). A parte sul do Cinturão Ribeira é dividida em dois terrenos, Apiaí e Curitiba, separados pela zona de falha Lancinha-Cubatão. Como resultado, o cinturão é dominado por terrenos de origens distintas, separados por zonas de cisalhamento (Heilbron et al., 2004; Faleiros, 2008; Faleiros et al., 2011; Santos et al., 2015).

Segundo Campanha et al. (2015), o Cinturão Ribeira é um largo domínio crustal paralelo à linha de costa do sudoeste do Brasil, cujos componentes foram consolidados, deformados e metamorfizados durante a Orogenia Brasiliana/Pan Africana. Este cinturão possui continuidade no Cinturão Kaoko e Congo do Oeste na parte oeste africana. As principais massas cratônicas envolvidas nesse processo colisional são os crátons São Francisco - Congo, Paranapanema e Luís Alves.

Ainda de acordo com Campanha \& Sadowski (1999), o Terreno Apiaí teve o começo de sua evolução no Paleo- e Mesoproterozoico e consiste em sequências supracrustais de baixo a médio grau metamórfico, originalmente designadas como Grupo Açunguí (Almeida, 1957; Petri \& Suguio, 1969), e posteriormente proposto como Supergrupo Açunguí (Campanha, 1991; Campanha \& Sadowski, 1999). Segundo Prazeres Filho et al. (2003), abrange uma faixa com aproximadamente $500 \mathrm{~km}$ de extensão e $100 \mathrm{~km}$ de largura, localizada na porção centro-sul do Cinturão Ribeira.

O Supergrupo Açunguí, de idade mesoproterozoica a ediacarana (Tassinari et al., 1990; Fiori, 1992, 1994; Hackspacher et al., 2000), teve a sua divisão estratigráfica na área definida em três unidades litotectônicas principais denominadas Formação Água Clara, Grupo Votuverava e Grupo Itaiacoca.

Datações minerais isotópicas U-Pb disponíveis (Hackspacher et al., 2000; Weber et al., 2004; Campanha et al., 2008, 2015; Siga Junior et al., 2009, 2011) indicam que o Terreno Apiaí foi formado pela amalgamação de unidades supracrustais cujas idades variam de Callimiano (1500-1400 Ma: Formação Água Clara e Grupo Votuverava) a Toniano (1000-900 Ma: parte do Grupo Itaiacoca) e a Ediacarano (630-580 Ma: parte do Grupo Itaiacoca).

A Formação Água Clara foi definida originalmente por Marini et al. (1967) e inserida no Supergrupo Açunguí. Aflora como uma faixa alongada de direção NE-SW. Nesta unidade ocorrem sedimentos siliciclásticos como mica xistos e lentes de quartzitos e químicos como mármores calcíticos puros e impuros, além de anfibolitos e rochas calciossilicáticas (Fiori, 1990).

O Grupo Votuverava, definido por Bigarella \& Salamuni (1958), é limitado a sul pela Zona de Cisalhamento Lancinha e a norte pelas zonas de cisalhamento Morro Agudo, Ribeira, Agudos Grandes e Figueira (Campanha, 1991). Segundo Campanha et al (2015), o Grupo Votuverava é composto predominantemente por rochas metassedimentares, metabásicas e metaultrabásicas e constitui-se de sucessões pelíticas metamorfizadas, geralmente interpretadas como turbiditos distais.

O Grupo Itaiacoca descrito por Bistrichi et al. (1985) foi definido inicialmente como formação por Almeida (1956) e corresponde a duas sequências sedimentares: uma terrígena e outra química.

O Complexo Granítico Três Córregos definido originalmente por Fuck (1967) consiste numa intrusão de formato ovalado, com $95 \mathrm{~km}$ de comprimento e largura aproximada de $25 \mathrm{~km}$, cujo maior eixo tem direção aproximada NE-SW (Cury et al., 2008). É composto por rochas monzoníticas, monzograníticas e granodioríticas, com termos tonalíticos, sienograníticos e dioríticos subordinados, pertencentes a granitoides do Tipo I, com tendência cálcioalcalina de alto K (Guimarães, 2000; Prazeres Filho et al., 2003).

Trabalho de cunho genético dos granitoides pós-orogênicos a anorogênicos da Faixa de 
Dobramentos Ribeira foi inicialmente proposto por Hasui et al. (1978), que individualizava os inúmeros corpos graníticos pós-tectônicos do estado de São Paulo. Pequenas alterações na sua delimitação ocorrem nos mapas geológicos de integrações do estado de São Paulo em escala
1:500.000 elaborado pelo Instituto de Pesquisa Tecnológica - IPT (Bistrichi et al., 1981; Almeida et al., 1981). Segundo Prazeres Filho et al. (2003) o período pós-colisional anorogênico é marcado pela intrusão de plútons graníticos rasos, incluindo o corpo granítico de Capão Bonito.

\section{GEOLOGIA LOCAL}

A área da Folha Topográfica de Guapiara (SG-22-X-B-II-2) na escala 1:50.000 do Instituto Brasileiro de Geografia e Estatística situa-se entre as coordenadas $48^{\circ} 30^{\prime}$ a $48^{\circ} 45^{\prime} \mathrm{W}$ e $24^{\circ}$ a $24^{\circ} 15^{\prime} \mathrm{S}$.

Este trabalho resultou da integração de mapeamentos geológicos em escala 1: 25.000, executados em partes da área da Folha Topográfica de Guapiara por trabalhos de campo da UNESP - Rio Claro, dados de literatura como Campanha (2002), Bolonini \& Godoy (2013) e evoluiu para trabalhos de mapeamento da folha, além de trabalhos que consistiram na homogeneização e integração de todas as unidades geológicas da área.

A estratigrafia da área é baseada no trabalho de Campanha (2002), com modificações propostas por Faleiros (2008), considerando-se as litologias mapeadas, os dados estruturais e a evolução metamórfica da região.

A área é representada por oito unidades estratigráficas: Formação Água Clara, grupos Votuverava e Itaiacoca, Complexo Granítico Três Córregos, Maciço Granítico Capão Bonito, Grupo Itararé, Formação Serra Geral e sedimentos do Quaternário (Figura 2).

A Formação Água Clara compreende a parte sul a sudeste da área. A norte, seu contato com os granitoides do Complexo Granítico Três Córregos ocorre através da Falha do Bairro dos Alves - Zona de Cisalhamento Quarenta Oitava. A formação é representada como um grande pacote de filitos sericíticos a quartzosos, com intercalações de metacalcários variados (mármores dolomítico a calcítico e calciossilicatadas) e lentes de diferentes tamanhos de anfibolitos (Figuras $3 \mathrm{~A}, \mathrm{~B}, \mathrm{C}$ ).

O Grupo Votuverava é representado pelos metassedimentos localizados entre duas grandes zonas de cisalhamento, localizado a sul do falhamento correlacionado à Zona de Cisalhamento Itapirapuã e a norte da Zona de Cisalhamento Quarenta Oitava.

O contato a sul com as rochas granitoides do
Complexo Granítico Três Córregos e do Maciço Granítico Capão Bonito, e os metassedimentos do Grupo Itaiacoca, respectivamente, ocorre por zonas de cisalhamento de empurrão, com desenvolvimento de foliações de baixo ângulo e dobras fechadas impressas nos metassedimentos.

O contato norte está encoberto pelos sedimentos do Grupo Itararé da Bacia Sedimentar da Paraná. É constituído por pacotes de quartzitos, quartzo xistos, xistos, além de lentes de actinolita-tremolita xistos e anfibolitos (Figuras 3 D, E, F).

O Grupo Itaiacoca é representado pelos metassedimentos localizados a norte da Zona de Cisalhamento Itapirapuã e das rochas granitoides do Complexo Granítico Três Córregos. A norte os contatos estão encobertos pelos sedimentos do Grupo Itararé da Bacia Sedimentar do Paraná. É constituído por pacotes de quartzitos, filitos, metarcóseos, calciossilicatadas, metarritmitos, além de lentes de rochas metabásicas (Figuras 3 G, H, I).

O Complexo Granítico Três Córregos aflora em contato com o Granito Capão Bonito no extremo leste da área e nos contatos noroeste e sudeste do corpo, disposto segundo a direção NE-SW.

São representados por biotita-hornblenda sieno- a monzogranitos porfiríticos de matriz média a grossa, de coloração acinzentada a rósea (Figuras $3 \mathrm{~J}, \mathrm{~K}$ ).

O contato noroeste se faz através da Falha de Capão Bonito, com imposição de uma deformação milonítica subvertical nas rochas granitoides Três Córregos, superposta a uma foliação de baixo ângulo associada às falhas de empurrão.

As rochas do Maciço Granítico Capão Bonito são constituídas dominantemente por sienogranitos vermelhos a rosados, hololeucocráticos a leucocráticos, inequigranulares de granulação média a grossa a levemente porfiríticas, isotrópicas a miloníticas nas regiões marginais do maciço ou em zona de deformação interna ao maciço (Figuras 3 L, M). 


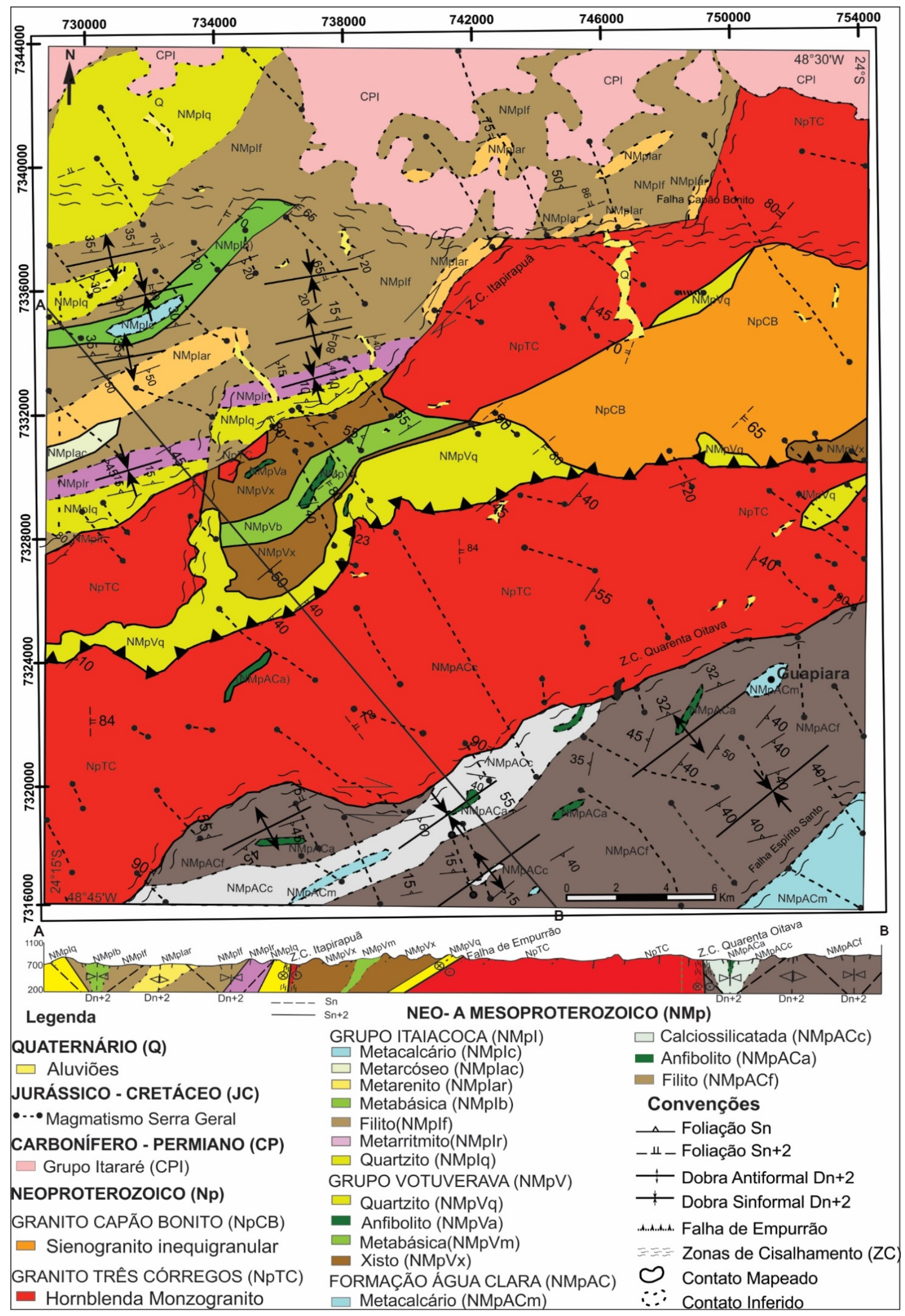

Figura 2 - Mapa Geológico da área da folha topográfica de Guapiara em 1:50.000. 
As rochas graníticas sin-colisionais do Granito Três Córregos e pós-colisionais do Granito Capão Bonito estão distribuídas na forma de corpos alongados e paralelos à direção das principais zonas de cisalhamento de direção NE-SW.

Estas zonas de cisalhamento constituem sistemas antigos, que facilitaram a ascensão destes magmas possibilitando o seu emplacement em estruturas geradas sob regimes transtensivos do tipo pull-apart, associadas às zonas de cisalhamento. Estas zonas foram reativadas no final do Neoproterozoico, condicionando a forma e as bordas do maciço.

O Grupo Itararé, na área de estudo, está localizado principalmente na porção norte, com a presença de arenitos mal selecionados, intercalados com argilitos e conglomerados (Figuras $3 \mathrm{~N}$ ).

Associado ao magmatismo básico da Formação Serra Geral ocorrem diabásios na forma de diques, que cortam as demais unidades, apresentam distintas dimensões e estão orientados preferencialmente em NW-SE (Figura $3 \mathrm{O}$ ).

As coberturas sedimentares são constituídas por depósitos recentes formados por argilas, siltes, areias, cascalhos, além de sedimentos coluvionares expostos pouco expressivos no sopé das principais serranias.

\section{GEOLOGIA ESTRUTURAL}

O quadro estrutural é determinado dominantemente pelo arranjo tectônico neoproterozoico, identificado nas rochas epimetamórficas do Supergrupo Açunguí e rochas granitoides.

As rochas apresentam uma evolução estrutural do tipo polifásica, evidenciada pelo registro de quatro fases deformacionais $D_{n}$, $D_{n+1}, \quad D_{n+2}$ e $D_{n+3}$. As deformações são registradas nos litotipos metassedimentares e em rochas metabásicas e, especificamente algumas fases, nos corpos graníticos.

As estruturas primárias em diversas situações encontram-se fortemente superpostas, devido aos intensos processos de transposição das foliações de baixo ângulo $S_{n}$ e $S_{n+1}$ e da deformação milonítica, associadas a uma foliação de alto ângulo $S_{n+2}$.

A manutenção das estruturas ocorre de forma escassa nas regiões com forte transposição milonítica, definindo somente um bandamento composicional tectônico.

Nas áreas menos deformadas, nas quais se destaca somente a deformação de baixo ângulo, pode ocorre, localmente, o acamamento gradacional reliquiar $S_{0}$. As deformações progressivas tangenciais $D_{n}$ e $D_{n+1}$ encontramse associadas ao início do processo colisional, associadas às zonas de cavalgamento e relacionadas às fases iniciais de empurrão da orogênese e consequente espessamento crustal.

$\mathrm{O}$ primeiro evento deformacional $D_{n}$ é responsável por dobramentos isoclinais a recumbentes, fechados, com foliação planoaxial $S_{n}$ de baixo a médio ângulo e direção preferencial N30E/30NW, subparalela ao bandamento composicional $\mathrm{S}_{0}$.

$O$ segundo evento deformacional $D_{n+1}$ constitui uma foliação plano-axial identificada por uma clivagem ardosiana penetrativa ou uma de clivagem de crenulação $S_{n+1}$ não penetrativa e espaçada milimétrica a centimetricamente entre porções da rocha.

Apresentam atitude N40W/30SW, com baixo a médio ângulos de mergulho. Localmente ocorrem as duas foliações $S_{n}$ e $S_{n+1}$, no entanto, quando paralelizadas nos flancos das dobras recumbentes é preservada apenas a foliação $S_{n+1}$.

A granitogênese sin- colisional associa-se a uma tectônica dúctil $\mathrm{D}_{\mathrm{n}+1}$ com emplacement das rochas do Complexo Granítico Três Córregos, vista principalmente na reorientação dos minerais máficos (biotita e hornblenda) e a geração de porfiroblastos nas auréolas de metamorfismo de contato desenvolvidas lateralmente aos corpos ígneos.

Esta relação estrutural, de uma foliação de baixo ângulo com corpos graníticos, ressalta o caráter sin-cinemático do emplacement magmático ao evento tectônico $\mathrm{D}_{\mathrm{n}+1}$ do Supergrupo Açunguí.

O terceiro evento deformacional $\mathrm{D}_{\mathrm{n}+2}$ envolve esforços transpressivos em caráter dúctil-rúptil e retrometamórfico e é definido pela formação de amplas dobras normais, marcadas na figura 2, suaves a abertas (sinformais e antiformais) e sanfonadas de eixo sub-horizontal, com uma tênue clivagem subvertical, com plano axial de atitude N60E/75SE. 

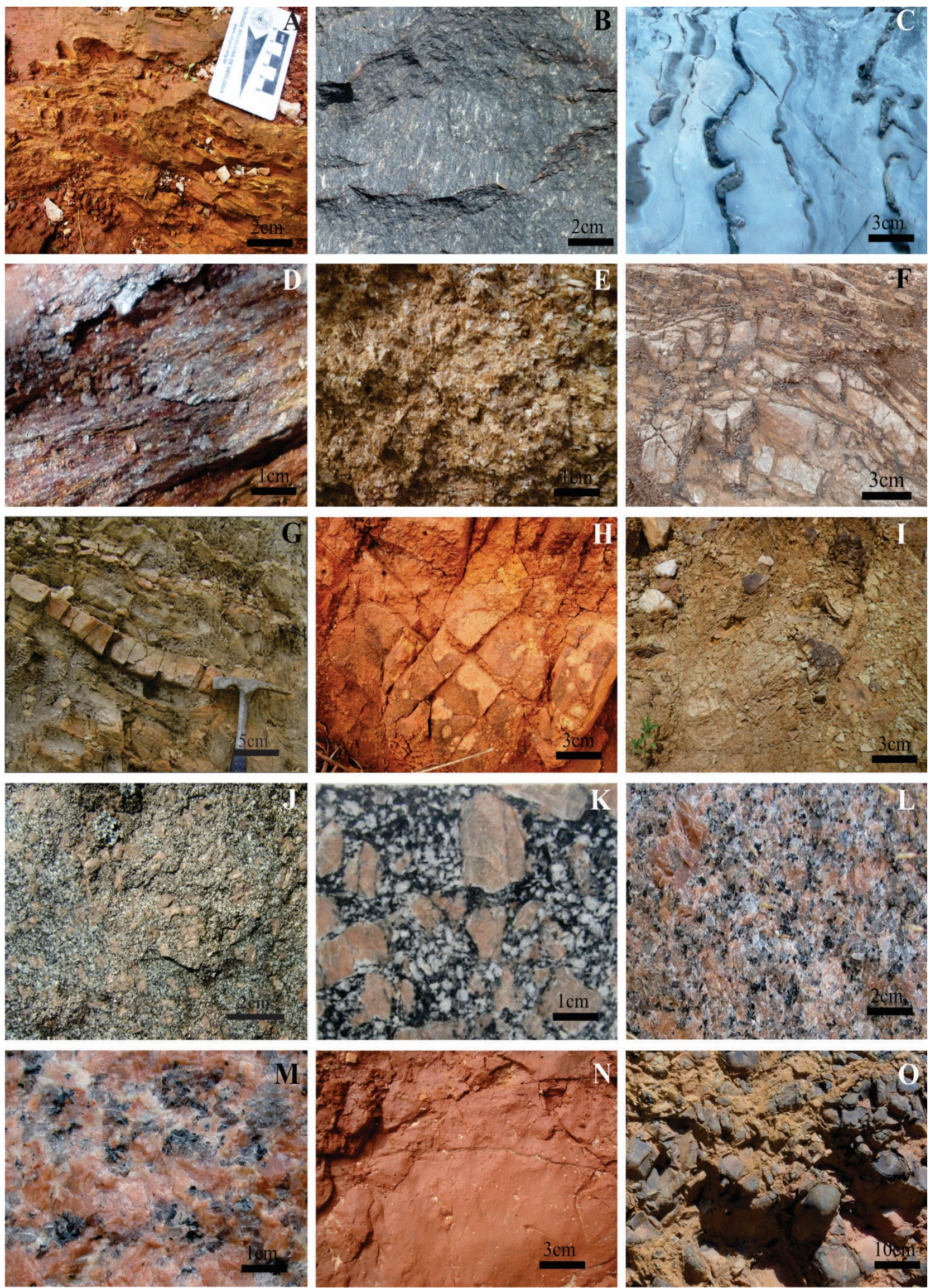

Figura 3 - Fotografias dos principais tipos petrográficos de rochas da Folha Topográfica Guapiara: A, B, C) Filito, anfibolito e metacalcário da Formação Água Clara. D, E, F) Muscovita xisto, actinolita xisto e quartzito do Grupo Votuverava. G, H, I) Quartzito, filito e actinolita xisto, do Grupo Itaiacoca. J, K) Hornblenda monzogranito do Complexo Granítico Três Córregos. L, M) Sienogranito róseo do Maciço Granítico Capão Bonito. N) Diamictito do Grupo Itararé. O) Diabásio associado ao magmatismo Serra Geral. 
Esta clivagem evolui gradativamente e localmente para falhas direcionais, com foliação milonítica e/ou cataclástica $S_{n+2}$, que afetam principalmente as bordas do corpo, paralelas ao trend regional NE-SW, ambas paralelas à direção geral NE-SW regional. A foliação $S_{n+2}$ é penetrativa nas zonas de cisalhamento, e apresenta indicativos de movimentos de caráter destral, definindo uma foliação milonítica, com a geração de filonitos com acamamento tectônico que oblitera estruturas reliquiares sedimentares e as paragêneses de metamorfismo de contato.

Associada à deformação $\mathrm{D}_{\mathrm{n}+2}$ ocorre a ascensão magmática tardia das rochas póscolisionais do Maciço Granítico Capão Bonito,

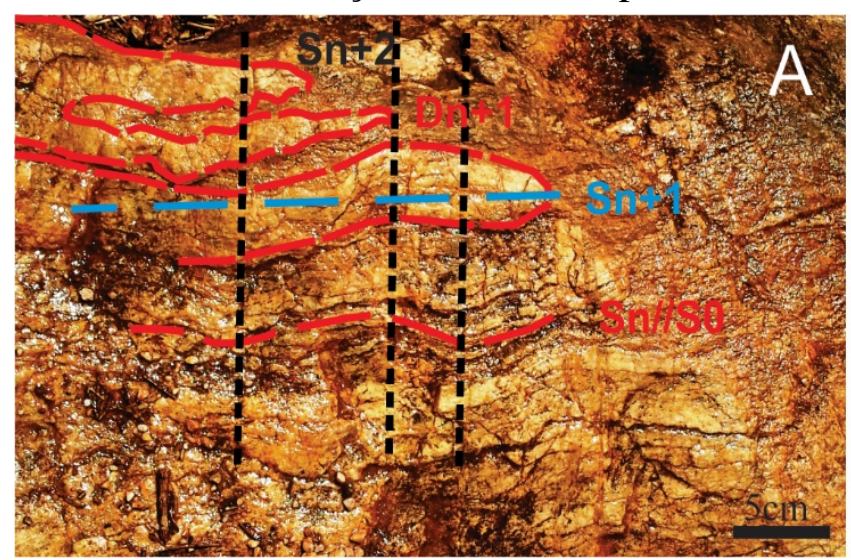

que se encontram associadas a zonas de cisalhamento, configurando sua atual estruturação alongada pela deformação do maciço.

A fase deformacional $\mathrm{D}_{\mathrm{n}+3}$ apresenta dobras locais, com plano axial com direção NW/SE, mas sem expressividade em toda a área. É marcada por uma tênue foliação ou clivagem de fratura de direção N45W/80SW.

Tardiamente observam-se diques básicos intrusivos controlados por um trend de direção principal NW-SE, que são correlatos aos diques e enxames de diques do Lineamento Guapiara (NW-SE) e que se encaixam na direção das juntas. A figura 4 integra as fases estruturais descritas.

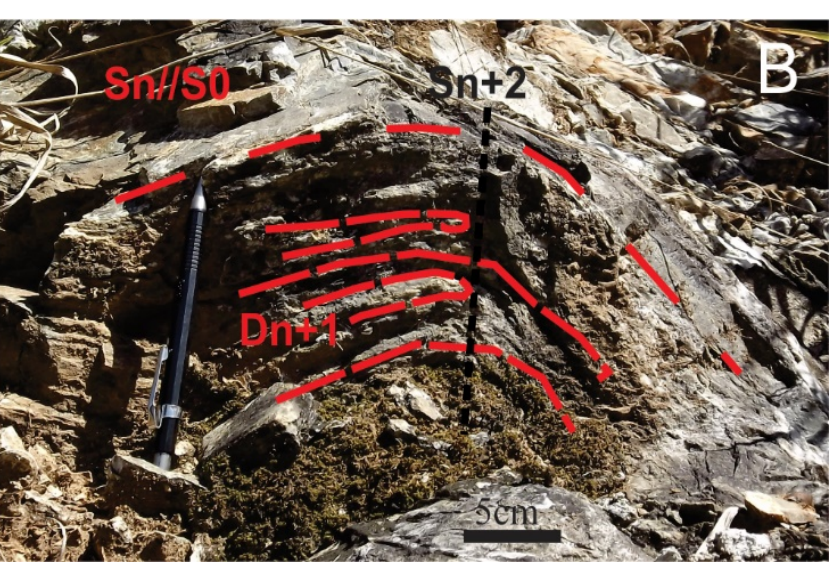

Figura 4. A, B) Exemplos de superposição de deformações na área, com a foliação $S_{n}$ dobrada pelo evento $D_{n+1} e$ dobras abertas a suaves com plano axial verticalizado pelo evento $D_{n+2}$.

\section{METAMORFISMO}

Os eventos metamórficos encontram-se diretamente correlacionados aos eventos estruturais e são caracterizados por $\mathrm{M}_{1}$ associado à deformação regional e a formação das foliações $S_{n}$ e $S_{n+1}$ do metamorfismo regional, $\mathrm{M}_{2}$ associado ao metamorfismo de contato, temporalmente correlacionado a $S_{n+1}$, e $\mathrm{M}_{3}$ associado ao metamorfismo dinâmico e retrometamórfico, correlacionado aos eventos $\mathrm{S}_{\mathrm{n}+2}$ e $\mathrm{S}_{\mathrm{n}+3}$.

O metamorfismo regional identificado nas rochas da área é do tipo dinamotermal (Barroviano), em fácies xisto-verde. Os eventos metamórficos foram descritos a partir dos principais litotipos: filitos, xistos, rochas carbonáticas e raras metabásicas.

Nas rochas dominantes na área, os filitos, predominam os minerais micáceos: clorita, sericita, muscovita e biotita. A paragênese de metamorfismo regional progressiva $\mathrm{M}_{1}$ associada a $\mathrm{S}_{\mathrm{n}}$ e $\mathrm{S}_{\mathrm{n}+1}$ é constituída por quartzo + sericita + clorita + muscovita + biotita. A paragênese quartzo + clorita + sericita é a associação metamórfica associada a $S_{n}$, raramente preservada, mas é acompanhada comumente por recristalizações de biotita e muscovita, o que constitui o ápice metamórfico. A fase metamórfica associada a $S_{n+1}$, auge do metamorfismo, é evidenciada pelo crescimento de biotita + muscovita, reorientação dos minerais da fase inicial e recristalização parcial de quartzo.

Nas rochas calciossilicáticas a paragênese é composta por quartzo + albita + carbonato + talco + actinolita + tremolita + epidoto. Raras metabásicas são descritas, com paragênese constituída por quartzo + albita + epidoto + hornblenda e, imposto a estes minerais, observa-se também paragênese de caráter retrometamórfico definida por actinolita + tremolita + clorita+ carbonato + epidoto.

Portanto, a presença de biotita em rochas 
metassedimentares, talco + tremolita em calciossilicatadas e hornblenda em metabásicas, define para a sequência de rochas da área um metamorfismo regional em fácies xisto verde médio-alto.

$\mathrm{O}$ metamorfismo de contato $\mathrm{M}_{2}$, associado ao emplacement granítico, é correlacionado ao período da deformação $\mathrm{S}_{\mathrm{n}+1}$, e apresenta pequena expressão areal, o que dificulta a delimitação das rochas hornfélsicas.

Os contatos das rochas metavulcanossedimentares com os corpos graníticos, de maneira geral, são tectônicos por zonas de cisalhamentos, o quem impõe as rochas maior um grau de deformação e transformações minerais retrometamórficas, e consequentemente, preservando parcialmente as paragêneses e texturas de feições de metamorfismo de contato.

O metamorfismo de contato é identificado pela recristalização dos filitos, gerando os micaxistos de ocorrência lateral aos corpos ígneos e pela presença de porfiroblastos de biotita nos metassedimentos, hornblenda nas metabásicas e nas calciossilicáticas quartzo + tremolita + epidoto + andesina + diopsídio, atingindo localmente fácies albita e hornblenda ou piroxênio hornfels.

O metamorfismo dinâmico $\mathrm{M}_{3}$ é intenso e vinculado a uma foliação milonítica e/ou cataclástica, com desenvolvimento localmente de filonitos com marcante bandamento tectônico que obliteram as estruturas reliquiares e as estruturas deformacionais mais antigas.

Quando atuante sobre os corpos graníticos é observado principalmente nas suas zonas marginais próximo aos seus contatos com as rochas metassedimentares e localmente nas regiões internas do corpo por falhas direcionais, sempre com direções paralelas às grandes zonas de cisalhamento desenvolvidas no final da fase $\mathrm{D}_{\mathrm{n}+2}$.

Este processo rúptil superpõe ao conjunto das rochas, a partir de transformações minerais retrometamórficas $\mathrm{M}_{3}$, o que desestabiliza as paragêneses para condições de fácies xistoverde baixa, com sericita + clorita nos filitos, tremolita/actinolita + clorita + epidoto nas calciossilicáticas e tremolita/actinolita + clorita + albita nas metabásicas.

\section{CONCLUSÕES}

A região de Guapiara corresponde a faixa centro-sul do Cinturão Ribeira inserida na parte central da Província Mantiqueira Central. O arcabouço geológico local envolve rochas da sequência metavulcanossedimentar do Supergrupo Açunguí, de idade mesoproterozoica, metamorfizadas e deformadas no Neoproterozoico, associadas a um conjunto de rochas granitoides geradas durante os episódios colisionais ligados à formação do Supercontinente Gondwana.

As principais unidades litoestratigráficas mapeadas na região são constituídas por metassedimentos da Formação Água Clara e dos grupos Votuverava e Itaiacoca de idade meso- a neoproterozoica, corpos graníticos neoproterozoicos do Complexo Granito Três Córregos e do Maciço Capão Bonito, rochas sedimentares do Grupo Itararé, intrusivas básicas da Formação Serra Geral e sedimentos quaternários.

O quadro estrutural-metamórfico é determinado dominantemente pelo arranjo tectônico final neoproterozoico, evidenciado nas rochas epimetamórficas por uma evolução estrutural do tipo polifásica. As estruturas primárias $\mathrm{S}_{0}$, devido aos intensos processos de transposição das foliações dúctil e deformação milonítica, apresentam-se preservadas de forma escassa em algumas áreas, com predomínio somente do acamamento gradacional reliquiar $\mathrm{S}_{0}$, nas áreas menos deformadas.

São registradas quatro fases deformacionais definidas pelas fases: $D_{n}$, de baixo a médio ângulo e direção preferencial NE/SW, subparalela ao bandamento composicional $\mathrm{S}_{0}$; a fase $D_{n+1}$, de baixo a médio ângulo e direção preferencial NE/SW. Associada à tectônica dúctil $\mathrm{D}_{\mathrm{n}+1}$, ocorre a colocação das rochas graníticas sin-colisionais do Complexo Três Córregos e a imposição de uma foliação $S_{n+1}$ nas rochas granitóides.

A fase $D_{n+2}$, de alto ângulo e direção preferencial NE/SW nas zonas miloníticas mascara as foliações antigas de baixo ângulo e, portanto, é a principal fase nestas áreas. Este processo dúctil superpõe o conjunto das rochas, a partir de transformações minerais retrometamórficas.

Associada à fase deformacional $D_{n+2}$ 
ocorrem a ascensão magmática e a atual estruturação alongada do Maciço Capão Bonito, com foliação milonítica e/ou cataclástica $\mathrm{S}_{\mathrm{n}+2}$, afetando principalmente as bordas do corpo, paralelas ao trend regional NE-SW. A fase $D_{n+3}$ de alto ângulo e marcada por uma tênue foliação ou clivagem de fratura de ocorrência localizada e direção preferencial NW/SE. As rochas graníticas sin-colisionais do Granito Três Córregos e pós- colisionais do Granito Capão Bonito estão distribuídas na forma de corpos alongados e paralelos às principais zonas de cisalhamento de direção NE-SW. Os eventos metamórficos são caracterizados pelo metamorfismo $\mathrm{M}_{1}$, o ápice metamórfico, do tipo regional progressivo na fácies xisto-verde alto a anfibolito baixo; $\mathrm{M}_{2}$, do tipo de contato em condições de baixa pressão e média a alta temperatura, com a formação local de hornfels e skarns e $\mathrm{M}_{3}$, metamorfismo regional e dinâmico de caráter retrometamórfico na fácies xisto-verde baixa.

\section{AGRADECIMENTOS}

Os autores agradecem ao apoio do CNPq, processo $n^{\circ}$ : 304614/2017-3.

\section{REFERÊNCIAS}

ALMEIDA, F.F.M. Novas ocorrências de fósseis no PréCambriano brasileiro. Anais da Academia Brasileira de Ciências, v. 29, n. 1, p. 63-72, 1957.

ALMEIDA, F.F.M. Origem e evolução da Plataforma Brasileira. Rio de Janeiro. Boletim DNPM/DGM, v. 241, 38p., 1967.

ALMEIDA, F.F.M.; HASUI, Y., BRITO-NEVES, B.B.; FUCK, R.A. Províncias estruturais brasileiras. In: SIMPÓSIO GEOLOGIA NORDESTE, 8, 1977. Campina Grande. Anais... Recife: Sociedade Brasileira de Geologia, p. 363391, 1977.

ALMEIDA, F.F.M.; HASUI, Y.; PONÇANO, W.L.; DANTAS, A.S.L.; CARNEIRO, C.D.R.; MELO, M.S.; BISTRICH, C.A. Mapa Geológico do Estado de São Paulo. Nota explicativa. São Paulo, IPT, Monografias 6, v. 1, 126p., 1981.

BASEI, M.A.S.; SIGA JUNIOR, O.; MACHIAVELLI, A.; MANCINI, F. Evolução tectônica dos terrenos entre os cinturões Ribeira e Dom Feliciano (PR-SC). Revista Brasileira de Geociências, v. 22, p. 216-221, 1992.

BASEI, M.A.S.; SIGA JUNIOR, O.; KAULFUSS, G.A.; CORDEIRO, H.; NUTMAN A.; SATO, K.; CURY, L.F.; PRAZERES FILHO, H.J.; PASSARELLI, C.R.; HARARA, O.M.; REIS NETO, J.M.; WEBER; W. "Geochronology and isotope geochemistry of Votuverava and Perau Mesoproterozoic Basins, Southern Ribeira Belt, Brazil” - In: SOUTH AMERICAN SYMPOSIUM ON ISOTOPE GEOLOGY (Short Papers), IV, 2003, São Paulo. Expanded Abstract....São Paulo: USP-IG.

BIGARELLA, J.J. \& SALAMUNI, R. Estudos preliminares na Série Açungui: VII - A Formação Votuverava. Curitiba, Instituto de História Natural, Boletim Geologia, v. 2, 60p., 1958.

BISTRICHI, C.A.; CARNEIRO, C.D.R.; DANTAS, A.S.L.; PONÇANO, W.L.; CAMPANHA, G.A.C.; NAGATA, N.; ALMEIDA, M.A.; STEIN, D.P.; MELO, M.S.; CREMINI, O.A. Mapa Geológico do Estado de São Paulo em 1: 500.000. IPT/Pró-Minério, São Paulo, v. 2, 1981.

BISTRICHI, C.A.; ALMEIDA, M.A.; STEIN, D.P. Geologia das folhas Barra do Chapéu (SG.22-X-B-I-4) e Araçaíba (SG.22-XF-II-3), estados de São Paulo e Paraná. São Paulo, Contrato IPT/ Pró-Minério, vol. l, 104 p. (IPT. Relatório 22.150), 1985.

BOLONINI, T.M. \& GODOY, A.M. Geologia e Geoquímica das rochas graníticas do Maciço Capão Bonito, SP. São Paulo. Geociências, v. 32, n. 3, p. 452-470, 2013.

BRITO NEVES, B.B. América do Sul: quatro fusões, quatro fissões e o processo acrescionário andino. Revista Brasileira de Geociências, v. 29, n. 3, p. 379-392, 1999.

CAMPANHA, G.A.C. Tectônica Proterozoica no Alto e Médio Vale do Ribeira, Estados de São Paulo e Paraná.
São Paulo, 1991. 296p. Tese (Doutorado), Instituto de Geociências, Universidade de São Paulo, 1991.

CAMPANHA, G.A.C. O papel do sistema de zonas de cisalhamento transcorrentes na configuração da porção meridional da Faixa Ribeira. São Paulo, 2002. 105p. Tese (Livre-Docência), Instituto de Geociências, Universidade de São Paulo, 2002.

CAMPANHA, G.A.C. \& SADOWSKI, G.R. Tectonics of the southern portion of the Ribeira Belt (Apiaí Domain). Precambrian Research, v. 98, p. 31-51, 1999.

CAMPANHA, G.A.C.; BISTRICHI, C.A.; ALMEIDA, M.A. Considerações sobre a organização litoestratigráfica e evolução tectônica da faixa de dobramentos Apiaí. In: SIMPÓSIO SUL-BRASILEIRO DE GEOLOGIA, 3. Curitiba, 1987. Atas...Curitiba: SBG, v. 2, p. 725-742, 1987.

CAMPANHA, G.A.C.; BASEI, M.A.S; TASSINARI, C.C.G.; NUTMAN, A.P.; FALEIROS, F.M. Constraining the age of the Iporanga Formation with shrimp U-Pb zircon: implications for possible ediacaran glaciation in the Ribeira belt, SE Brazil. Gondwana Research, v. 13, p. 117-125, 2008.

CAMPANHA, G.A.C.; FALEIROS, F.M.; BASEI, M.A.S.; TASSINARI, C.C.G.; NUTMAN, A.P.; VASCONCELOS, P.M. Geochemistry and age of mafic rocks from the Votuverava Group, southern Ribeira Belt, Brazil: Evidence for $1490 \mathrm{Ma}$ oceanic back-arc magmatism. Precambrian Research, v. 266, p. 530-550, 2015.

CHIODI FILHO, C.; TAKAHASHI, A.T.; SILVA, C.R.; FERREIRA, J.C.G. Projeto Capão Bonito. Relatório Final CPRM, v. I, Rio de Janeiro, 121 p., 1983.

COMPANHIA DE PESQUISA DE RECURSOS MINERAIS. Geologia e Recursos Minerais do Estado de São Paulo: Sistemas de Informações Geográficas (SIG). Brasília: MME, Programa Geologia do Brasil: Integração, Atualização e Difusão de Dados da Geologia do Brasil, Mapas Geológicos Estaduais. Escala 1:750000, CD-ROM, 2006.

CURY, L.F.; SIGA JUNIOR, O.; HARARA, O.M.M.; PRAZERES FILHO, H.J.; BASEI, M.A.S. Aspectos tectônicos das intrusões dos granitos do Cerne, Passa Três e Rio Abaixo, Sudeste do Pré-Cambriano paranaense. Estudo baseado em datações ${ }^{39} \mathrm{Ar}-{ }^{40} \mathrm{Ar}$ em Micas. Geologia USP. Série Científica, v. 8, n. 1, p. 87-104, 2008.

FALEIROS, F.M. Evolução de Terrenos TectonoMetamórficos da Serrania do Ribeira e Planalto do Alto Turvo (SP, PR). São Paulo, 2008. 306p. Tese (Doutorado), Instituto de Geociências da Universidade de São Paulo, 2008.

FALEIROS, F.M.; CAMPANHA, G.A.C.; BELLO, R.M.S.; FUZIKAWA, K. Quartz recrystallization regimes, c-axis texture transitions and fluid inclusion re-equilibration in a prograde greenschist to amphibolite facies mylonite zone 
(Ribeira Shear Zone, SE Brazil). Tectonophysics, v. 485, p. 193-214, 2010.

FALEIROS, F.M.; FERRARI, V.C.; COSTA, V.S.; CAMPANHA, G.A.C. Geoquímica e petrogênese de metabasítos do grupo Votuverava (Terreno Apiaí, Cinturão Ribeira Meridional): evidências de uma bacia retro arco caliminiana. Geologia USP, Série Científica, v. 11, n. 2, p. 135-155, 2011.

FASSBINDER, E. A unidade Água Clara no contexto do Grupo Açungui: um modelo transpressivo de colisão oblíqua no Neoproterozóico paranaense. São Paulo, 1996. 207p. Tese (Doutorado), Instituto de Geociências Universidade de São Paulo, 1996.

FIORI, A.P. Tectônica e estratigrafia do Grupo Açungui a norte de Curitiba. São Paulo. 1990. 261p. Tese (Livre Docência), Instituto de Geociências - Universidade de São Paulo, 1990.

FIORI, A.P. Tectônica e estratigrafia do Grupo Açungui, PR. Boletim IG-USP. Série Científica, v. 23, p. 55-74, 1992.

FIORI, A.P. Evolução geológica da bacia Açungui. Boletim Paranaense de Geociências, v. 42, p. 7-27, 1994.

FUCK, R.A. Contribuição ao estudo das rochas graníticas do Estado do Paraná. Boletim Paranaense Geociências. v. 23/25, p. 183-221, 1967.

FUCK, R.A.; BRITO NEVES, B.B.; SCHOBBENHAUS, C. Rodínia descendants in South America. Precambrian Research, v. 160, n. 1-2, p 108-126, 2008.

GUIMARÃES, G.B. As rochas granitóides do Complexo Granítico Cunhaporanga, Paraná: Aspectos geológicos, geofísicos, geoquímicos e mineralógicos, São Paulo, 2000. 230p. Tese (Doutorado), Instituto de Geociências Universidade de São Paulo.

HACKSPACHER, P.C. \& GODOY, A.M. Vertical Displacement During Post-Colisional Escape Tectonic (Brasiliano Orogeny) of The Ribeira Belt, São Paulo, Brazil. Journal of African Earth Sciences. Elsevier Science Ltd., Africa do Sul, v. 29, n. 1, p. 25-32, 1999.

HACKSPACHER, P.C.; DANTAS, E.L.; SPOLADORE, A.; FETTER, A.H., OLIVEIRA, M.A.F. Evidence of Neoproterozoic back arc basin development in the Central Ribeira Belt, Southeastern Brazil new geochronological and geochemical constraints from São Roque Açungui groups. Revista Brasileira de Geociências, v. 30, n. 1, p. 110-114, 2000.

HASUI, Y. A grande Colisão Pré-Cambriana do Sudeste brasileiro e a Estruturação Regional. São Paulo Geociências, v. 29, n. 2, p. 141-169, 2010.

HASUI, Y. Sistema Orogênico Mantiqueira. In: HASUI, Y., CARNEIRO, C.D.R., ALMEIDA, F.F.M.A., BARTORELLI, A. (org.) Geologia do Brasil. São Paulo, Beca, p. 331-372, 2012.

HASUI, Y. \& OLIVEIRA, M.A.F. Província Mantiqueira. Setor Central. In: ALMEIDA, F.F. DE \& HASUI, Y. (Eds). O Pre-Cambriano do Brasil. São Paulo, p. 308-344, 1984.

HASUI, Y.; CARNEIRO, C.D.R.; BISTRICHI, C.A. Os Granitos e Granitóides da Região de Dobramentos Sudeste nos Estados de São Paulo e Paraná. In: CONGRESSO BRASILEIRO DE GEOLOGIA, 30, Recife. Anais... Recife: SBG, p. 2579-2593, 1978

HEILBRON, M.; PEDROSA-SOARES, A.C.; CAMPOS NETO, M.C.; SILVA, L.C. TROUW, R.A.J.; JANASI, V. A. Província Mantiqueira. In: MANTESSO NETO, V., BARTORELLI, A., CARNEIRO, C.D.R., BRITO-NEVES, B.B. (Eds.) 2004. Geologia do Continente Sul-americano: São Paulo: Ed. Beca, p. 203-236, 2004.

MARINI, O.J.; TREIN, E.; FUCK, R.A. O Grupo Açungui no Estado do Paraná. Boletim Paranaense de Geociências, v. 23/25, p. 43-103, 1967.

PETRI, S. \& SUGUIO, K. Sobre os metassedimentos do grupo Açungui do extremo sul do estado de São Paulo. São Paulo.
Secretaria de Serviços e Obras Públicas/Faculdade de Filosofia, Ciências e Letras da USP, p. 1-98, 1969.

PITCHER, W.S. Granites types and tectonic environments. In. Mountain Building Processes. K. Hsii (Ed.). Academic Press, p. 19-40, 1983.

PRAZERES FILHO, H.J.; HARARA, O.M.; BASEI, M.A.S.; PASSARELLI, C.R.; SIGA JUNIOR, O. Litoquímica, geocronologia $\mathrm{U}-\mathrm{Pb}$ e geologia isotópica (Sr-Nd-Pb) das rochas graníticas dos batólitos Cunhaporanga e Três Córregos na porção sul do Cinturão Ribeira, Estado do Paraná. Boletim IG-USP/ Série Científica, São Paulo, v. 3, p. 51-70, 2003.

REIS NETO, J.M. Faixa Itaiacoca: registro de uma colisão entre dois blocos continentais no Neoproterozoico. São Paulo. 1994. 296p. Tese (Doutorado), Instituto de Geociências - Universidade de São Paulo.

RENNE, P.R.; DECKART, K.; ERNESTO, M.; FÉRAUD, G.; PICCIRILLO, E.M. Age of the Ponta Grossa dike swarm (Brazil), and implications to Paraná flood volcanism. Earth and Planetary Science Letters, v. 144, p. 199-211, 1996.

SANTOS, T.M.B.; TASSINARI, C.C.G; FONSECA, P.E. Diachronic collision, slab break-off and long-term high thermal flux in the Brasiliano-Pan-African orogeny: Implications for the geodynamic evolution of the Mantiqueira Province. Precambrian Research, v. 260, p. 1-22, 2015.

SIGA JUNIOR, O. Domínios tectônicos do Sudeste do Paraná e nordeste de Santa Catarina: geocronologia e evolução crustal. São Paulo, 1995. 212p. Tese (Doutorado), Instituto de Geociências, Universidade de São Paulo.

SIGA JUNIOR, O.; BASEI, M.A.S.; PASSARELLI, C.R.; SATO, K.; CURY, L.F.; MCREATH, I. Lower and Upper Neoproterozoic magmatic records in Itaiacoca Belt (ParanáBrazil):zircon ages and lithostratigraphy studies. Gondwana Research, v. 15, p. 197-208, 2009.

SIGA JUNIOR, O., BASEI, M.A.S., SATO, K., PASSARELLI, C.R., NUTMAN, A., MCREATH, I., PRAZERES FILHO, H.J. Calymmian (1.50-1.45 Ga) magmatic records in Votuverava and Perau sequences south-southeastern Brazil: zircon ages and $\mathrm{Nd}-\mathrm{Sr}$ isotopic geochemistry. Journal of South American Earth Sciences. v. 32, p. 301-308, 2011.

SOARES, P.C. Sequências tectonossedimentares e tectônica deformadora no centro-oeste do escudo paranaense. In: SIMPÓSIO SUL-BRASILEIRO DE GEOLOGIA, 3. Curitiba, 1987. Atas...Curitiba: SBG, v. 2, p. 743- 771, 1987.

SOARES, P.C. Tectônica colisional em torno do bloco Paraná, Brasil. In: CONGRESSO LATINO-AMERICANO DE GEOLOGIA, 7. Belém, 1988. Anais... Belém: SBG, v. 1, p. 63-79, 1988.

TASSINARI, C.C.G.; BARBOUR, A.P.; DAITX, E.C.; SATO. $\mathrm{K}$. Aplicação dos isótopos de $\mathrm{Pb}$ e $\mathrm{Sr}$ na determinação da natureza das fontes das mineralizações de chumbo do Vale do Ribeira - SP e PR. In: CONGRESSO BRASILEIRO DE GEOLOGIA, 36. Natal. 1990. Anais... Natal: SBG. n. 3, p. 1254-1266, 1990.

VIEIRA, O.A.R.P. Geologia da Folha Guapiara 1:50000 (SG-22-X-B-II-2). Rio Claro. 2017，145p. Dissertação (Mestrado)- Instituto de Geociências e Ciências Exatas, Universidade Estadual Paulista.

WEBER, W.; SIGA JÚNIOR, O.; SATO, K.; REIS NETO, J.M.; BASEI, M.A.S.; NUTMAN, A.P. A Formação Água Clara na região de Araçaíba - SP: registro de uma bacia mesoproterozoica. Geologia USP, Série Científica, v. 4, p. 101-110, 2004

Submetido em 20 de março de 2017 Aceito em 21 de fevereiro 2018 